\title{
ESCRITAS MARGINAIS NAS RUAS: EXPRESSÕES DO DIREITO VISUAL À CIDADE
}

\section{MARGINAL WRITTEN IN STREETS: EXPRESSIONS OF VISUAL RIGHT TO THE CITY}

\author{
Claudio Oliveira Carvalho ${ }^{1}$ \\ Carla Neves Mariani ${ }^{2}$
}

\section{Resumo}

Este trabalho é um convite para o olhar em direção aos diferentes modos - legais e ilegais - de ocupação dos espaços urbanos por meio da Cultura de Rua. A arte urbana, representada aqui pelas escritas urbanas marginais, compõe uma complexa rede de manifestações artísticas e culturais que cumprem a função social da cidade ao ressignificar seus espaços, inscrevendo neles identidades e memórias. Tal narrativa guia-se a partir das intersecções e conflitos existentes entre a arte urbana e a produção do Direito. Mais especificamente, busca-se reconhecer que as escritas marginais urbanas são expressões legítimas da reapropriação e ocupação das cidades pelas minorias, sendo assim manifestações de um Direito Visual à Cidade. Como suporte metodológico, este texto se orientou pela pesquisa etnográfica, observando as narrativas das ruas, seus modos de produção e de percepção pela cidade. Fundamental foi também a revisão bibliográfica, apoiada no diálogo com fontes jurídico-legais que versam sobre o tema.

Palavras-chave: Cultura de Rua; Escritas Urbanas; Direito à Cidade; Direito Cultural.

\begin{abstract}
This research is an invitation to look at the different ways - legal and illegal - of occupying urban spaces through Street Culture. Urban art, now represented by the marginal urban writings, composes a complex network of artistic and cultural manifestations that fulfill city's social function, by re-signifying its spaces, inscribing it identities and memories. This narrative is guided by the intersections and conflicts between urban art and the production of law. More specifically, it seeks to recognize that urban marginal writing is a legitimate expression of city's reappropriation and occupation by minorities, thus being manifestations of a Visual Right to the City. As a methodological support, this text was guided by ethnographic research, observing street narratives and its modes of production and perception by the city. Fundamental was also the bibliographical review, supported in the dialogue with legal The work that begins is an invitation to look at the different ways - legal and illegal - of occupying urban spaces through Street Culture. Urban art, represented here by the marginal urban writings, composes a complex network of artistic and cultural manifestations that fulfill the social function of the city by re-signifying its spaces, inscribing in them identities and memories. This narrative is guided by the intersections and conflicts between urban art and the production of law. More specifically, it seeks to recognize that urban marginal writing is a legitimate expression of the reappropriation and occupation of cities by minorities, thus being manifestations of a Visual Right to the City. As a methodological support, this text was guided by ethnographic research,

\footnotetext{
${ }^{1}$ Doutor em Desenvolvimento Regional e Planejamento Urbano. Docente na Universidade Estadual do Sudoeste da Bahia (UESB). Integrante do Núcleo de Assessoria Jurídica Alternativa (NAJA) e coordenador do Grupo de Pesquisa Direito e Sociedace (GPDS). E-mail: ccarvalho@uesb.edu.br

2 Bacharela em Direito da Universidade Estadual do Sudoeste da Bahia (UESB). Integrante do Núcleo de Assessoria Jurídica Alternativa (NAJA) e do Grupo de Pesquisa Direito e Sociedade (GPDS). E-mail: c_mariani@outlook.com
} 
observing the narratives of the streets, their modes of production and perception by the city. Fundamental was also the bibliographical review, supported in the dialogue with legal-legal sources that deal with the subject.sources that deal with the subject.

Keywords: Street Culture; Urban Writings; Right to the City; Right to Culture.

\title{
INTRODUÇÃO
}

\author{
[...] [Q]ue faço parte dessa gente \\ que pensa que a rua \\ é a parte principal da cidade3.
}

Como primeiro passo desse rolê, ${ }^{4}$ tomemos as ruas da cidade como caminho de percepções. A cidade - com sua pluralidade de signos e significados, seu cotidiano de encontros e de violência, seus valores e preços e, mais importante, com seus sujeitos - mais do que objeto de estudo, representa aqui o espaço por excelência da vida e da produção dos direitos.

Todavia, há que se admitir que tamanha circulação de interesses faz do espaço público lugar do conflito, da exposição de diferenças, como coloca Mauro lasi:

É a unidade de contrários, não apenas pelas profundas desigualdades, mas pela dinâmica da ordem e da explosão. As contradições, na maioria das vezes, explodem, cotidianamente, invisíveis. As contradições surgem como grafites que insistem em pintar de cores e beleza a cidade cinza e feia. Estão lá, pulsando, nas veias que correm sob a pele urbana. ${ }^{5}$

Viver nas cidades é conviver com as segregações territoriais provocadas pela mercantilização dos espaços: quem não pode pagar é empurrado para as periferias. Os processos de urbanização nas grandes e médias cidades distanciam uma parcela significativa da população dos centros urbanos, e, consequentemente, dos serviços de saúde e saneamento básico, do acesso à educação, dos espaços de lazer e de cultura - enfim, de uma totalidade de direitos considerados básicos para todo indivíduo.

Em paralelo e como reação a essa segregação sócio-espacial, insurge-se nas cidades a arte urbana, protagonizada pela juventude periférica e manifestada por um conjunto de valores, práticas e modos de vida formadores de identidades plurais, que possuem em comum a função de reivindicar espaço e visibilidade.

\footnotetext{
${ }^{3}$ LEMINSKI, 2013, p. 24.

${ }^{4}$ Gíria utilizada entre os pichadores para se referir à prática de sair pela cidade para pichar (escrever ou desenhar em paredes e muros).

${ }^{5}$ IASI, 2013, p. 41.
} 
Nesse contexto, a inscrição do indivíduo na cidade, em sentido político, se dá justamente pela via da cultura. Gravar marcas de sua presença na paisagem, como registro de sua passagem, é uma prática pré-histórica dos seres humanos. No universo urbano, território do multiculturalismo, o sujeito contemporâneo imprime novas linguagens nas ruas: são suas marcas, adesivos, tags, grafites e pichos que promovem novos sentidos para os espaços urbanos e modificam a identidade da cidade.

Ao marcarem suas presenças e resistências na cidade, os jovens criam novos moldes de constituição identitária e de práxis espacial - eixos comuns aos indivíduos, aos movimentos políticos e à sociedade - delineando uma postura de agentes dispostos a transpor os muros construídos pelos processos perversos de urbanização. É para assumir a posição de sujeito político que, por meio da Cultura de Rua, a juventude periférica encontra caminhos para inverter a lógica de desapropriações legais, apropriando-se ilegalmente dos muros, paredes, prédios e concretos impostos pelo Capital. Revela-se aqui, portanto, a intrínseca relação construída entre a arte de rua e o Direito à Cidade - direito de pertencer, de percorrer, de modificar e de ser visto na cidade.

"Escritas marginais urbanas" é o termo escolhido aqui para representar todas as marcas urbanas (grafite, pichação, lambe-lambe, tags, adesivos, estêncil, o grapixo, o bombing, as frases de conteúdo poético e político etc.) que se consolidam como representação artística e cultural da cidade, manifestação essa, em grande parte, de cunho identitário, estético e político de determinado grupo, especialmente de jovens vindos da periferia. É importante salientar que não há a pretensão de negar a originalidade de cada uma dessas expressões gráficas; reconhece-se as especificidades de cada uma - seus estilos, seus autores, suas dinâmicas de criação. Entretanto, por uma questão textual, optou-se por condensar todas elas numa conceituação só.

Admitir as manifestações dos sujeitos sociais na cidade, as ocupações, os usos, as formas de expressão cultural é, para além das formalizações, entender e valorizar o uso e a democratização da cidade, à luz do texto Constitucional ${ }^{6}$, que preleciona ser dever do Estado a garantia do pleno exercício dos direitos culturais por todos, apoiando e incentivando a valorização e difusão de manifestações culturais, conforme seu artigo 215. Em descompasso, as legislações infraconstitucionais não reconhecem tais manifestações como elemento constituinte da cultura urbana das cidades: pelo contrário, marginalizam- -nas. A tipificação da

\footnotetext{
${ }^{6}$ BRASIL, 1988.
} 
pichação como crime ambiental na Lei n. 9.605, de 12 de fevereiro de 19987 , e como dano ao patrimônio no art. 163 do Código Penal ${ }^{8}$ revela a tensão existente entre o direito político produzido nas ruas e o direito normatizado nas leis.

Partindo da concepção de cidade como meio de experiência da linguagem, provoca--se um diálogo entre o direito normatizado e as expressões gráficas urbanas. Diante disso, propõese um enfrentamento às construções jurídico-legais que não reconhecem tais expressões político-artísticas como elementos do processo de formação da memória coletiva e individual urbana.

O conflito entre as escritas marginais e as normas jurídicas é sintoma de um cenário político-social de recuo na garantia de direitos em que se asseveram os mecanismos legais de cerceamento das liberdades de expressão e de protesto, em que a criminalização dos movimentos sociais é o modus operandi de controle social e de descaracterização de suas pautas políticas.

Destarte, faz-se necessário reconhecer que as ruas são espaços constantes de construção de novos direitos. Ouvir o saber das ruas através das escritas urbanas é dar visibilidade e legitimidade às formas de vivência e expressão na cidade que consistem em efetiva participação política dos sujeitos na formação do patrimônio cultural urbano.

A fonte primeira de manifestação do Direito são as inter-relações sociais. As construções e práticas legais que se pretendam justas e democráticas não podem se afastar da compreensão dos novos movimentos que ocupam as cidades. Insurgem-se da prática social, na reivindicação de direitos novos, muitas vezes em contraposição ao ordenamento jurídico posto. Para solucionar esses conflitos, o caminho é a interpretação inspirada no texto Constitucional e na defesa da materialidade dos direitos fundamentais em seu sentido amplo, com o objetivo de fazer cumprir a função social das cidades. Este texto é um convite para o olhar. Para o encontro com as ruas. Para o Direito que emerge de sua fonte natural - o povo - e de seu protagonismo a partir da rua ${ }^{9}$.

\section{FUNÇÃO SOCIAL DA PROPRIEDADE E DAS CIDADES}

A rua grita.

$\begin{array}{rrrrr}\text { A rua grita e não é escutada pelos juízes, } \\ \text { advogados, } & \text { teóricos } & \text { do } & \text { Direito, professores } & {[\ldots]}\end{array}$

\footnotetext{
7 BRASIL, 1998.

8 BRASIL, 1940.

${ }^{9}$ SOUZA JÚNIOR, 2008.
} 
temos que reaprender a escutar a rua enquanto produtora do novo. ${ }^{10}$

O crescimento do modelo de ocupação espacial fundado na hipervalorização do capital, representado pela captura do público pelo privado, transforma os centros urbanos em polos econômicos marcados por grandes empreendimentos, verticalização da cidade e especulação imobiliária, espaços pensados para privilegiar a circulação de mercadorias e que se multiplicam, em detrimento da diminuição das áreas verdes e dos espaços livres.

Como resposta, o surgimento de novos modos de ocupação marginal da cidade, representados pela luta por moradia, transporte público, trabalho e outros, têm sido determinantes para a configuração de conflitos entre a propriedade, o meio ambiente ecologicamente equilibrado e o Direito à Cidade. Tais modos de ocupação exploram as contradições do atual modelo de urbanização e seus prejuízos para a cidade, além de exporem as disputas por espaço e direitos na urbe.

As escritas marginais urbanas se inserem nesse contexto como representação desses novos modos de reapropriação do espaço urbano, mas, além disso, têm em si o enfrentamento à lógica da cidade-mercadoria e a sua principal expressão: a propriedade privada. Diante disso, não é à toa que, na primeira vez que o ato de pichar ou grafitar apareceu no ordenamento jurídico brasileiro, a norma penal incriminadora tinha como bem a ser tutelado o patrimônio. A cultura urbana questiona, portanto, se o muro pode pertencer também à rua, ao lado de fora, às pessoas que pertencem à cidade e não somente ao proprietário.

A produção jurídica majoritária, profundamente associada ao pensamento neoliberal, insiste no pressuposto de que os direitos fundamentais - sobretudo os direitos de liberdade são em princípio ilimitados, sendo que qualquer intervenção na liberdade é considerada medida excepcional. Em contrapartida, há uma segunda linha teórica que sustenta que deve haver um sistema de equilíbrio e um condicionamento recíproco entre os bens jurídicos constitucionais, uma espécie de cláusula de comunidade, impedindo que um bem jurídico seja "absolutizado" às custas de outro. Neste sentido, disserta Gaio:

Em suma, a determinação do conteúdo dos direitos fundamentais decorre de uma dimensão objetiva, a qual fundamenta explicitamente a correlação entre direitos e deveres a fim de que se garanta a satisfação, ao máximo possível, dos direitos individuais aos valores comunitários, como a saúde e o meio ambiente. Ademais, as limitações aos direitos fundamentais não servem apenas para exprimir uma relação de

\footnotetext{
${ }^{10}$ WARAT, 2010, p. 53.
} 
solidariedade, mas igualmente proporcionam a concretização dos direitos individuais. ${ }^{11}$

A Constituição Brasileira de 1988, por sua vez, qualifica a propriedade como instituto jurídico (direito à propriedade) e como direito subjetivo (direito de propriedade) ainda que funcionalizado. Deve haver, portanto, uma inescusável conformação entre as demandas privadas e públicas, de modo que a propriedade não tenha apenas utilidade para o titular do domínio, mas atenda também aos variados interesses da coletividade, conforme as diferentes exigências sociais existentes em cada momento histórico; é nisso que se sustenta o princípio da função social da propriedade.

Ao traçar condicionamentos e limites ao conteúdo do direito de propriedade urbana, reconhece-se que ela não constitui apenas um bem patrimonial, mas também é suporte imprescindível à concretização de diversos direitos fundamentais, como ao meio ambiente, à infraestrutura, à moradia e aos demais elementos que permitem o usufruto equitativo das cidades. De fato, a Constituição estabelece que: "A propriedade urbana cumpre sua função social quando atende às exigências fundamentais de ordenação da cidade expressas no plano diretor."12. Ao regular os modos de ocupação do espaço urbano, o Plano Diretor Urbano não se limita a apenas estabelecer condições de igualdade entre os proprietários; deve, sobretudo, assegurar intervenções urbanísticas correlacionadas à proteção dos valores ambientais e do Direito à Cidade ao conjunto dos seus habitantes.

Todavia, mesmo diante de uma clara e precisa legislação, é frequente perceber que o exercício positivo do Direito, em função das tensões engendradas no espaço urbano, ainda desconsidera as variáveis previstas na Lei Maior, prevalecendo, assim, o caráter absoluto da propriedade privada, em detrimento de outros direitos. Duas razões principais podem ser relacionadas para explicar esse fato: a pretensão de neutralidade dos tribunais, sob o argumento de que este conteúdo cabe à Administração Pública, e a dicotômica relação entre valor de uso e valor de troca.

Lefebvre $^{13}$, ao defender a construção de um Direito à Cidade, destaca a oposição entre o valor de uso (a cidade e a vida urbana, o tempo urbano) e o valor de troca (os espaços comprados e vendidos, o consumo dos produtos, dos bens, dos lugares e dos signos). 0 processo de urbanização vivenciado pelas cidades atualmente inverte a função da cidade e

\footnotetext{
${ }^{11} \mathrm{GAIO}, 2015$, p. 103.

12 BRASIL, 1988, p. 81 .

${ }^{13}$ LEFEBVRE, 2006.
} 
atribui a ela valor de troca, subordinando a realidade urbana a um modelo hegemônico que ignora suas características locais. Galil complementa:

O urbanismo emudeceu a cidade e se revestiu de uma forma de dominação, fundada exclusivamente na técnica. Aos administradores e urbanistas passou despercebido que a cidade desejada tem que ser o fruto do trabalho e participação coletivos de uma sociedade e o lugar onde se materializa a história de um povo, pela via das suas relações sociais, políticas, econômicas, artísticas e religiosas. ${ }^{14}$

Uma das principais consequências dessa fragmentação do espaço da cidade é a redução - e até mesmo o desaparecimento - dos espaços públicos de uso comum para os encontros e trocas cotidianas, chancelados muitas vezes por instrumentos legais. Bauman ${ }^{15}$ aponta que um território despojado de espaço público dá pouca chance para que as normas sejam debatidas, para que os valores sejam confrontados e negociados, promovendo separação e segregação espacial.

A criminalização das intervenções visuais urbanas, sob a justificativa de uma suposta necessidade de ordem - cujos atributos são higiene, simetria e beleza dos espaços - representa exemplo concreto desta conjuntura. Como resistência, mas, sobretudo, como sobrevivência a este modelo segregacionista de urbanização, as escritas marginais urbanas avançam sob o tecido das cidades, imprimindo suas identidades por meio de uma linguagem própria e contribuindo para a ressignificação desses territórios.

A mesma cidade que nega as escritas urbanas, sob um falso pretexto de limpeza visual e de proteção ambiental, acolhe sem restrições o fluxo insistente dos signos produzidos pela publicidade. Na visão da cidade como bem de consumo, até mesmo a linguagem e a estética tornam-se valor de troca, pois é importante que se desperte desejos de consumidor. Para Lefebvre $^{16}$, a publicidade tende a incorporar a arte, a literatura e a poesia e a suplantá-las, ao as utilizar como retóricas.

Carvalho e Rodrigues afirmam que "[...] quanto mais a população citadina se conscientizar das causas das mazelas urbanas, quanto mais se apropriar das diversas instâncias de participação popular, mais a cidade será um reflexo de suas perspectivas." ${ }^{17}$. O princípio da função social, ao incidir sob o conteúdo do direito de propriedade urbana, abre caminho para uma cidade democrática que, conforme Lefebvre ${ }^{18}$, é a proclamação e realização da vida

\footnotetext{
14 GALIL, 2005, p. 6-7.

15 BAUMAN, 1999.

16 LEFEBVRE, 2006.

${ }^{17}$ CARVALHO; RODRIGUES, 2016, p. 71.

18 LEFEBVRE, 2006.
} 
urbana como reino do uso (da troca e do encontro, separados do valor de troca) assegurando, assim, outras dimensões do Direito à Cidade.

\title{
MEIO AMBIENTE URBANO
}

\author{
Não busque nojo em meio ao lixo da cidade \\ morta \\ Pra se livrar dos bichos da cidade morta \\ Pra se livrar dos vícios da cidade. ${ }^{19}$
}

A luta pela função social das cidades está atrelada à construção de espaços urbanos mais democráticos. Nesse contexto, o meio ambiente urbano precisa representar a confluência dos mais diversos elementos formadores da urbe: ambiente, sociedade, cultura e economia.

O intenso crescimento econômico das últimas décadas e seus irreversíveis efeitos sobre as cidade e paisagens - com redução dos recursos naturais e da biodiversidade e com a poluição - despertaram a necessidade permanente de regulação do meio ambiente pelo Direito. Foi a partir da Conferência das Nações Unidas sobre o Meio Ambiente, em 1972, que os Estados e as organizações mundiais reconheceram formalmente, como direito fundamental, o desfrute de condições de vida adequadas em um meio cuja qualidade permita ao indivíduo levar uma vida digna e gozar de bem-estar, ou seja, assegurou-se o meio ambiente como um direito que pertence ao gênero humano.

Tal resolução firmou-se na compreensão de que, na medida em que é pressuposto para o exercício de direitos como a vida e a saúde das populações, o equilíbrio ambiental deve ocupar posição central no sistema de direitos fundamentais. Utilizando como base o posicionamento de José Afonso da Silva ${ }^{20}$, é justamente em virtude desse efeito irradiante que se constitui a formulação unitária de meio ambiente, a partir da interação do conjunto de elementos naturais, culturais e artificiais.

O reconhecimento de um direito fundamental ao meio ambiente impôs aos ordenamentos jurídicos de todo o mundo a construção de uma cultura constitucional que levasse em consideração os interesses ambientais para garantir as condições básicas relacionadas à globalidade dos seus elementos. Além disso, o expresso reconhecimento de um direito subjetivo ao meio ambiente permite que a sua proteção ocorra de maneira autônoma em relação aos demais valores constitucionais.

\footnotetext{
19 PASSAPUSSO, 2013, p. 1.

20 SILVA, 1981.
} 
No Brasil, foi somente com a criação da Política Nacional do Meio Ambiente, Lei n. 6.938, de 31 de agosto de $1981^{21}$, que a preservação, melhoria e recuperação da qualidade ambiental se firmaram como matéria de um texto normativo, visando assegurar, no país, condições ao desenvolvimento socioeconômico, aos interesses da segurança nacional e à proteção da dignidade da vida humana. Seguindo essa mesma linha de raciocínio, com a Lei n. 7.347 , de 24 de julho de $1985^{22}$, foi disciplinado um conjunto de elementos processuais para defender as ameaças e lesões ao meio ambiente, por intermédio da Ação Civil Pública de responsabilidade por danos causados ao meio ambiente, ao consumidor, a bens e direitos de valor artístico, estético, histórico, turístico e paisagístico.

A Constituição Federal de 1988 recepcionou esta mesma noção de meio ambiente dado pela Lei n. 6.938/81, caracterizando-o por diferentes aspectos: meio ambiente natural, meio ambiente artificial, meio ambiente do trabalho e meio ambiente cultural, delimitado em seu art. 216. Embora existam bens singulares e suas respectivas estruturas de proteção, o ponto de intersecção e de justificação de todas as políticas ambientais é a busca permanente pelo equilíbrio ecológico e pela sadia qualidade de vida.

Sob o argumento da proteção ao meio ambiente artificial (conjunto de todo o espaço construído e dos espaços habitáveis pelo homem) foram inseridos no ordenamento jurídico brasileiro infraconstitucional institutos específicos para obstar quaisquer degradações na qualidade ambiental desses espaços. Destacam-se a poluição visual e o dano ambiental, pois, para a doutrina jurídica, as expressões gráficas urbanas aqui estudadas assim podem ser classificadas.

Antes de iniciarmos o diálogo sobre a tipificação dessa atividade, é salutar conhecermos os conceitos basilares dessa tipificação. A poluição visual diz respeito ao acúmulo de interferências nos espaços urbanos que degradem a qualidade das edificações, ruas e praças públicas, modificando a paisagem natural ou urbana e prejudicando, direta ou indiretamente, a saúde, a segurança e o bem-estar da população, bem como afetando as condições estéticas ou sanitárias do meio ambiente. Contudo, o conceito mais abrangente é aquele que diz que há poluição visual quando o campo visual do cidadão se encontra de tal maneira obstaculizado que a sua percepção dos espaços da cidade é impedida ou dificultada.

Por outro lado, entende-se como dano ambiental aquilo que causa uma lesão ao meio ambiente. Os danos que atingem interesses relativos a bens materiais - representando sua

\footnotetext{
${ }^{21}$ BRASIL, 1981.

22 BRASIL, 1985.
} 
deterioração ou perda - são chamados de patrimoniais; já aqueles que ofendem interesses não corpóreos - representados pelos valores imateriais da pessoa humana - são classificados como extrapatrimoniais.

Até o advento da Lei n. 9605/98 23 , o ato de intervir visualmente no espaço urbano era punido como crime de dano contra o patrimônio, previsto no artigo 163 do Código Penal atual. Esse tipo penal consiste em destruir, inutilizar ou deteriorar patrimônio alheio. Nesse sentido, é perfeitamente aceitável a tese de que as escritas urbanas jamais poderiam ter sido enquadradas como crime de dano, pois, conforme Cripta Djan exemplifica, ao se referir à prática da pichação,

[...] o pixo não INUTILIZA uma parede, um muro. O muro continua apto a cumprir sua função. Mas seu SIGNIFICADO muda. A ressignificação do espaço público por meio de intervenções estéticas constitui uma importante tradição da arte contemporânea, excedendo a esfera da própria pixação, vetor mais radical da arte urbana, que acaba por sofrer uma discriminação descabida. ${ }^{24}$

A desproporcionalidade do enquadramento dessas intervenções artísticas no tipo penal elencado fica também evidente quando se leva em conta a sua natureza efêmera, caracterizada por sua fácil remoção - seja pela ação do tempo, seja por uma limpeza. Enquanto o muro é uma agressão física, o ato de intervir visualmente no espaço urbano é uma agressão estética e, portanto, pode-se julgar que, desde as primeiras normatizações sobre o assunto, existe uma espécie de censura criminalizadora quanto ao uso do espaço urbano.

Seguindo essa lógica criminalizatória, em 1998 as expressões gráficas urbanas foram inseridas no direito ambiental, tanto no ambiente artificial quanto no ambiente cultural, pela Lei n. 9.605/98 (Lei dos Crimes Ambientais) ${ }^{25}$, posteriormente alterada pela Lei n. 12.408, de 25 de maio de $2011^{26}$, que tutela os direitos ambientais a serem protegidos. No texto inicial, todos os atos de inscrições não autorizadas no espaço urbano eram entendidos como atos de "conspurcação", ou seja, "cobrir de imundície, sujar, macular, aviltar, corromper".

Na última alteração legal, o legislador descriminaliza a prática do grafite, ao citá-la como excludente e ao utilizar somente as expressões pichar (escrever ou rabiscar dizeres de qualquer espécie em fachadas, muros, prédios, monumentos, entre outros) ou conspurcar (sujar, manchar) na tipificação do crime. O ordenamento jurídico brasileiro é o único no mundo em que sua legislação normatiza, de modo dicotômico, duas categorias de intervenções visuais no

\footnotetext{
23 BRASIL, 1998.

24 DJAN, 2015, p. 49, grifos do autor.

${ }^{25}$ BRASIL, 1998.

${ }^{26}$ BRASIL, 2011.
} 
espaço urbano. De um lado, há a punição do indivíduo que picha, baseada no conceito de "conspurcação" e, por outro, há, como excludente, uma proteção ao patrimônio cultural e à arte do grafite. Desde que realizado com a autorização do proprietário, o grafite é elevado ao status de arte, enquanto a pichação segue criminalizada e equiparada ao ato de sujar, macular e manchar.

Restam ainda tentativas atuais de majoração do quantum penal destinado à prática. Em março de 2015, foi proposto na Câmara dos Deputados o PL n. 985, de 27 de abril de 2015²7, que originalmente propunha o aumento da pena para o crime de pichação de seis meses a dois anos de detenção e multa, bem como determinava a perda de benefícios de usuários dos programas do Governo Federal, tais como a Bolsa Família, Bolsa Alimentação, Programa Nacional de Acesso ao Ensino Técnico e Emprego (PRONATEC), Programa Universidade para Todos (PROUNI), dentre outros. Como justificativa, o autor do projeto de lei se valeu de argumentos que demonstram uma construção baseada em preconceitos e estereótipos acerca dos sujeitos-artistas que riscam as cidades:

A prática do crime resta ainda mais reprovável quando atribuída a beneficiários de programas e benefícios sociais concebidos pelo Governo Federal, por configurar verdadeiro acinte à sociedade como um todo, que recursos públicos tenham sua destinação desvirtuada para a prática de crimes contra o patrimônio das cidades e contra o meio ambiente. ${ }^{28}$

Ao longo do processo legislativo o projeto sofreu alterações, sendo, em seu texto final, revogadas as inconstitucionais penalidades de perda de benefícios sociais e determinada "[...] prestação de serviços à comunidade, pelo prazo máximo de 5 (cinco) meses, preferencialmente em ações de conservação de edificações, patrimônio ou vias públicas [...] e [...] reparação do dano à vítima." 29 . O projeto segue para aprovação no Senado.

Tendo como norte de compreensão as construções conceituais e principiológicas que oferecem base à proteção legal ao meio ambiente natural, artificial e cultural nas cidades, conclui-se que os modos de ocupação dos espaços urbanos utilizados pelas juventudes - seja com riscos, seja com desenhos coloridos e elaborados - não possuem real potencial de degradação ao ambiente, pois não produzem quaisquer riscos ao bem-estar da população, bem como não são capazes de inutilizar as fachadas que preenchem.

Posto isso, evidencia-se a natureza meramente criminalizatória das legislações que versam sobre esse conteúdo. Evidencia-se que não se trata de um conflito entre a liberdade de

\footnotetext{
27 BRASIL, 2015a.

28 BRASIL, 2007 apud LARRUSCAHIM; SCHWEIZER, 2014, p. 26.

${ }^{29}$ BRASIL, 2015b, p. 1.
} 
expressão desses jovens e a proteção ao meio ambiente da cidade. Trata-se de um confronto com a propriedade privada e com valores estéticos pré-estabelecidos que objetivam normatizar e controlar as expressões artística e culturais urbanas.

\title{
CRIMINALIZAÇÃO DA ESTÉTICA DA PERIFERIA
}

\author{
Marginal é quem escreve à margem, \\ deixando branca a página \\ para que a paisagem passe \\ e deixe tudo claro à sua passagem. ${ }^{30}$
}

A dicotômica tipificação penal referente às intervenções gráficas urbanas, que coloca o grafite como exceção, mas criminaliza as demais formas de expressão, nos desperta uma importante questão: qual o elemento essencial capaz de diferenciar tais expressões, tornando uma arte e a outra um desvio marginal? É preciso compreender de que forma se dá o processo de criminalização das artes que riscam e desenham os muros da cidade e para isso tomamos como ponto de partida os estudos da Criminologia Cultural referentes às subculturas desviantes.

Afastando-se do olhar reducionista que compreende o movimento de ocupação dos espaços urbanos como essencialmente desviante ou marginal, isento de significados outros senão o de ilicitude, é possível perceber que as intervenções visuais no espaço urbano fornecem elementos éticos e estéticos para a análise criminológica, pois são, sobretudo, a representação visual de uma prática complexa, de sujeitos diversos.

A partir da busca pelos significados expressos pelas experiências desviantes, a preocupação da criminologia cultural está direcionada ao encontro com a identidade dos agrupamentos de jovens das grandes e médias cidades, observando também as formas como as agências de punitividade têm atuado. Percebe-se nessa atuação das agências do sistema penal a repressão às inúmeras manifestações dos movimentos de juventude (incluindo até mesmo um simples encontro entre grupos) influenciada e legitimada pela insistente difusão de rótulos pela mídia. Desta forma, meios de comunicação e polícia engendram um processo político contemporâneo de criminalização dos movimentos sociais.

Essa política repressiva e criminalizatória destinada aos movimentos protagonizados pela juventude periférica tem provocado um cenário preocupante de violência, produzido, principalmente, pelas instituições de controle penal, seja pela sua ação comissiva, seja por

${ }^{30}$ LEMINSKI, 2008, p. 1.

Revista de Direito da Cidade, vol. 09, no 3. ISSN 2317-7721 pp. 912-932 
omissão. Segundo o Mapa da Violência $2014^{31}$, dos 56 mil homicídios que ocorrem por ano no Brasil, mais da metade vitimam os jovens e, dos que morrem, $77 \%$ são negros e moradores da periferia. A Comissão Parlamentar de Inquérito (CPI) que investigou esses casos de violência contra jovens negros e pobres no Brasil concluiu que essa parcela da população vem sendo vítima de uma espécie de "genocídio simbólico".

Essa violência institucional é elemento constante nas letras das músicas (rap, funk, hip hop) e nas pichações, grafites, estêncil, grapixo, lambe-lambe, tornando tais manifestações, além de um fenômeno cultural urbano e uma referência estética na paisagem plural das cidades, verdadeiros instrumentos de denúncia. Todavia, seu desdobramento perverso é a exclusão violenta dos jovens da periferia, a partir da criminalização de suas práticas.

Embora nem sempre essas escritas carreguem conteúdo político explícito, a imagética por elas produzida já é por si só uma forma de dar visibilidade às desigualdades sociais. Contra o tédio e os processos de exclusão da vida cotidiana, tomando por base elementos ideológicos e estéticos, os jovens não apenas instituem uma subcultura do desvio, mas uma verdadeira contracultura, colocada como crítica aos valores formais. Complementando este raciocínio,

[...] as subculturas de resistência, de reação e de desespero, florescem e desaparecem, relembrando-nos que algo permanece errado, que o mundo social cresce cada vez mais instável e fissíparo. Aqui, crime e desvio espelham a desordem do cotidiano. ${ }^{32}$

As escritas marginais integram a memória coletiva urbana e relembram que as ruas são espaços de encontros, de trocas de ideias e de olhares. Entretanto, o que é visível para uns, muito frequentemente, não é para outros. O grande desafio dos códigos visuais é o de afetar a ordem, promovendo novas percepções nas pessoas, para que, enfim, se reconheça a presença desse Outro com tudo aquilo que se aplicaria a ele próprio: a alteridade.

Eis que o gesto estético se transforma em dispositivo de denúncia social, ao tornar visíveis as identidades que estão à margem do processo de urbanização das cidades atuais. A identidade se relaciona a processos de autoconstrução, de visibilidade, com aquilo que se representa aos outros, pelos objetos como símbolos de status e de posição na sociedade. É no exercício do buscar os significados presentes nas subjetividades deste fenômeno reativo da cultura urbana, verificando suas especificidades, no que tange aos seus (possíveis) comportamentos desviantes, suas relações de convivência, regras, práticas e simbologias, que será possível a construção de uma cultura jurídico-penal alicerçada na efetiva proteção aos

\footnotetext{
31 WAISELFISZ, 2014.

32 FERRELL; HAYWARD; YOUNG, 2010 apud CARVALHO, 2011, p. 172.
} 
direitos humanos. Para os jovens grafiteiros, pichadores, artistas de rua, a transgressão possui sentido de liberdade, e não de infringir a lei.

\section{DIREITO À CULTURA URBANA}

Entre urbanoides insanos, eu elevo meu ser A rua é nois e nunca vai deixar de ser [...]. ${ }^{33}$

A cidade, por ser espaço de passagens e de diversidade, é também espaço de convergências e conflitos. Nessa dinâmica, o Outro, o diferente, é colocado à margem. A cultura urbana, por seu potencial transformador e por seu caráter de movimento, inverte o jogo, colocando-se no centro das atenções. Por ser "o Outro" e falar a linguagem "do Outro", as escritas urbanas se reencontram com a cidade de direitos.

Em cidades marcadas por um modelo de urbanização excludente e espoliativo, em que a liberdade de se mover e de agir sobre o espaço urbano é privilégio de poucos, de que forma é possível concretizar o Direito à Cidade dos não proprietários? Como permitir o usufruto equitativo das cidades por todos os habitantes? Destaca-se, nesses conflitos, o Estatuto das Cidades, Lei n. 10.257, de 10 de julho de $2001^{34}$, encarregado, pela Constituição, de definir os significados da função social da cidade e da propriedade urbana, bem como de fixar importantes princípios básicos que irão nortear ações em favor da coletividade, da segurança e do bem-estar dos indivíduos e do equilíbrio ambiental.

Entretanto, o Estatuto da Cidade delegou parte de sua tarefa aos municípios, a ser cumprida por meio de seus Planos Diretores Urbanos, oferecendo para as cidades um conjunto inovador de instrumentos de intervenção sobre seus territórios, além de uma nova concepção de planejamento e gestão urbanos. Mesmo com essa ramificação, o conteúdo do Estatuto da Cidade é bastante amplo. Aqui nos interessa ressaltar duas de suas principais diretrizes, pois são as que melhor dialogam com o tema em debate: a preservação do meio ambiente cultural e a gestão participativa.

Como já dito anteriormente, o meio ambiente ecologicamente equilibrado não depende apenas dos espaços naturais protegidos, mas igualmente do conjunto de intervenções urbanísticas que visem preservar o meio ambiente construído (patrimônio cultural, histórico, artístico, paisagístico e arqueológico). Esta é mais uma importante medida para se obter a

\footnotetext{
33 EMICIDA, 2013, p. 1.

34 BRASIL, 2001.
} 
garantia da convivência vital entre o homem e o meio, bem como para a manutenção da história urbana, seja ela local, regional ou nacional. O texto legal assim institui:

Art. 2ㅇ. As funções sociais da cidade e da propriedade urbana serão definidas a partir da destinação de cada porção do território do município bem como da identificação dos imóveis não edificados, subutilizados e não utilizados, no caso de sua existência, de forma a garantir:

I. Espaços coletivos de suporte à vida na cidade, definindo áreas para atender as necessidades da população de equipamentos urbanos e comunitários, mobilidade, transporte e serviços públicos, bem como áreas de proteção, preservação e recuperação do meio ambiente natural e construído, do patrimônio cultural, histórico, artístico, paisagístico e arqueológico [...]..$^{35}$

Um Direito à Cidade justa contempla, de forma multidisciplinar, facetas de diversos direitos fundamentais. Não é suficiente, por exemplo, que o Poder Público ofereça habitações populares, é necessário criar condições para que as cidades possam ser espaços para o livre habitar. Não é suficiente prever em suas legislações a edificação de espaços de lazer, é necessário que os espaços públicos não sejam apenas pontos de passagem, mas sim lugares que possibilitem a convivência urbana e, consequentemente, a construção da diversidade de expressões culturais. Ao distinguir lugar e espaço. Em análise da obra de Anthony Giddens, Stuart Hall coteja lugar e espaço:

O lugar é específico, concreto, conhecido. A modernidade separa o espaço do lugar, reforçando relações entre ausentes. Os lugares permanecem "fixos"; é neles que temos raízes. O espaço pode ser cruzado em um piscar de olhos. O espaço, além de transitório, é visto como passagem e é feito para não ser ocupado. Não há sentimento de pertencimento. Quando muito, ele pode ser instrumentalmente utilizado para consumo. ${ }^{36}$

Todo e qualquer espaço da cidade pode ser convertido em lugar, mediante as ocupações, os usos e as formas de expressão cultural dos sujeitos sociais que nele ocorrem. Assim como meio ambiente urbano não se limita à paisagem natural, ambiente cultural não se resume ao patrimônio histórico constituído, compreende também as novas vivências culturais, os movimentos urbanos que ocupam e ressignificam a cidade. A Cultura de Rua, representada aqui pelas expressões gráficas urbanas, é exemplo vivo da manifestação destes novos sentidos do Direito à Cidade.

Além disso, o pleno exercício dos direitos culturais é reconhecido pelo texto Constitucional, em seu artigo $215^{37}$. É dever do Estado apoiar e incentivar a valorização e

\footnotetext{
35 BRASIL, 2005, p. 89.

36 SOUZA, 2014, p. 133.

37 BRASIL, 1988.
} 
difusão de manifestações dos diversos grupos de Cultura de Rua, que fazem uso dos espaços públicos como forma de sobrevivência e de reconhecimento. Em sentido semelhante, a Carta Mundial do Direito à Cidade define, em seu primeiro artigo, que:

1. Todas as pessoas devem ter o direito a uma cidade sem discriminação de gênero, idade, raça, etnia e orientação política e religiosa, preservando a memória e a identidade cultural em conformidade com os princípios e normas que se estabelecem nesta carta.

2. A cidade é um espaço coletivo culturalmente rico e diversificado que pertence a todos os seus habitantes.

3. As Cidades em corresponsabilidade com as autoridades nacionais se comprometem a adotar medidas até o máximo de recursos que disponham, para conseguir progressivamente, por todos os meios apropriados, inclusive em particular a adoção de medidas legislativas e normativas, a plena efetividade dos direitos econômicos, sociais, culturais e ambientais sem afetar seu conteúdo mínimo essencial. ${ }^{38}$

Ademais, para além das formalizações jurídicas, o reconhecimento e a expansão das culturas urbanas colaboram com a valorização do uso e da democratização da cidade, ao mesmo tempo em que propiciam o questionamento da imposição e do predomínio do sentido absoluto da mercantilização sobre ela.

A Cultura de Rua, em sua forma e em seu discurso político, reivindica justamente a concretização das diretrizes já positivadas pelo Estatuto da Cidade: o direito de todos os habitantes à terra urbana, à moradia, ao saneamento ambiental, à infraestrutura urbana, ao transporte e aos serviços públicos, ao trabalho e ao lazer, não só para as gerações atuais, como também para as futuras.

A necessidade de uma gestão democrática das cidades, pautada na participação popular urbana nas decisões de interesse público, bem como na sua organização, através de associações e movimentos sociais, é mais um dos importantes instrumentos de inclusão previstos pelo Estatuto da Cidade. Porém, tal estrutura tecno-formal não é capaz de produzir, na prática, mecanismos eficientes de envolvimento direto da população, pois apenas reconhece como legítimas as formas institucionalizadas de participação.

Os modos de participação e de intervenção no meio urbano genuinamente populares porque são produzidas no seio da cidade, fruto natural de suas demandas - seguem, via de regra, marginalizados. Destarte, o Direito, cúmplice da ordem econômica, e seus textos legais, facilmente manipuláveis de acordo com os rumos políticos que se quer tomar, não dão conta das multifacetadas realidades vividas e sentidas na cidade.

38 FÓRUM SOCIAL DAS AMÉRICAS; FÓRUM MUNDIAL URBANO, 2004, p. 2. 
O dever do Direito não pode se resumir à formalização de instrumentos como Estatuto da Cidade, Leis Orgânicas, Plano Diretor, Lei dos Crimes Ambientais. É substancial que se rompa com sua posição formal/tecnicista, a fim de ir ao encontro das questões da cidade de modo mais plural, com participação efetiva dos membros da comunidade, resgatando não só as esferas públicas de debate, mas privilegiando uma ocupação do território e uma aplicação de recursos que sejam democráticas e inclusivas.

A cidade é o lugar da produção do bem comum, de sentimentos e anseios que só se concretizam na diversidade que a vida urbana oferece. O Direito à Cidade nada mais é do que o direito à vida urbana, ao uso pleno dos seus caminhos. Por meio da arte, da disputa das narrativas, os sujeitos coletivos enfrentam o urbanismo - criador de uma cidade legal e de outra marginal - na busca por identidade, autonomia, participação e direitos, para que a cidade exerça, enfim, sua função social.

\section{CONSIDERAÇÕES FINAIS}

"Temos que reaprender a escutar a rua enquanto produtora do novo." ${ }^{39}$. É com o auxílio das palavras lúcidas e poéticas acima que encerramos este rolê pela cidade de direitos e por seus muros de escritas marginais. Assim como a arte ressignifica as cidades, o que aqui se propõe é a ressignificação do Direito formal, partindo da sua aproximação com os movimentos culturais que disputam seu lugar identitário no cenário urbano.

Gravar marcas de sua presença na paisagem, como registro de sua passagem, é uma prática pré-histórica dos seres humanos. No universo urbano, território do multiculturalismo, o sujeito contemporâneo imprime novas linguagens nas ruas: são suas marcas, adesivos, tags, grafites e pichos, que promovem novos sentidos para os espaços urbanos e modificam a identidade da cidade.

A cidade polo de contradições é também terreno fértil para manifestações multiculturais (feiras livres, hip hop, funk, grafite, pichação, trabalho ambulante), que desempenham a função social de preservação da autenticidade e identidade dos sujeitos citadinos. E aqueles afastados da cidade legal, por conta dos processos de segregação sócioespacial, representados pela juventude periférica, de que forma influenciam na formação da identidade da cidade? Por meio das escritas urbanas e fazendo o caminho inverso: da periferia ao centro.

${ }^{39}$ REVISTA DIREITO E SENSIBILIDADE, 2011, p. 1. 
O Direito pode estar nas construções legislativas, mas também vai além delas. Neste cenário de profundas contradições, manifestadas concretamente nas disposições sócioespaciais da cidade, as ruas são lugares de permanente construção de novos direitos, protagonizados pelos sujeitos políticos que nelas intervêm.

As sociedades urbanas vivem em uma tensão entre regulação e emancipação. De um lado, o Estado, exercendo por sua autoridade os comandos do Capital e, de outro lado, os sujeitos coletivos, reivindicando a concretização de direitos fundamentais. Nesse impasse, a marginalização ou até mesmo a criminalização destes movimentos é o recurso mais utilizado para silenciá-los ou neutralizá-los, sob o pretexto de regulação social.

Diante disso, a teimosia em riscar os muros consiste num enfrentamento às construções jurídico-legais que marginalizam tais expressões artísticas, negando seu caráter cultural, histórico e identitário. São elas manifestações de nossa cultura, e não crime ambiental contra o ordenamento urbano e o patrimônio cultural.

O direito ao patrimônio cultural - ou direito à cultura - é um direito fundamental previsto na Constituição de 1988, estabelecendo como bases para essa formação os bens de natureza material e imaterial, tomados individualmente ou em conjunto, portadores de referência à identidade, à ação, à memória dos diferentes grupos formadores da sociedade brasileira. Constatou-se, efetivamente, um conflito entre esses dispositivos constitucionais e a Lei Federal n. 9.605/98.

O Direito Visual à Cidade é a síntese totalizante da convergência de múltiplos fluxos de expressão urbana. O direito de aparecer na cidade é um direito de todos os cidadãos e se ramifica nos direitos de estar e ser, no direito de ir e vir, no direito à autenticidade e à expressão. Desmontar os padrões estéticos de nosso tempo é, neste momento, a mais profunda atitude política contra o autoritarismo cotidiano e espetacular que alimenta a indústria cultural da fachada.

A Cultura de Rua, anunciada pelas pichações, grafites, adesivos, lambe-lambe, tags, estênceis, é a linguagem de resistência das juventudes periféricas. É por meio dela que falam, que se tornam visíveis e presentes para a cidade. É assim que muitas verdades da vida urbana se expressam em seus muros, e a maior de todas elas é a urgência de pensar numa cidade para se viver.

No percurso do Direito Visual à Cidade, da periferia ao centro, as escritas marginais urbanas provocam variadas percepções (positivas e negativas) em seus espectadores, e a mais 
clara e sincera de todas elas é a compreensão de que o muro pode pertencer à rua, ao lado de fora, ao meio ambiente urbano, e não só ao dono da propriedade.

\section{REFERÊNCIAS BIBLIOGRÁFICAS}

BAUMAN, Zygmunt. Globalização: as consequências humanas. Rio de Janeiro: Zahar, 1999.

BRASIL. Constituição da República Federativa do Brasil. Promulgada em 5 de outubro de 1988. . Diário Oficial [da] República Federativa do Brasil, Brasília, DF, 5 out. 1988. Disponível em: <https://goo.gl/LWE8hk>. Acesso em: 23 fev. 2016

Lei no 10.257, de 10 de julho de 2001. Regulamenta os arts. 182 e 183 da Constituição Federal, estabelece diretrizes gerais da política urbana e dá outras providências. Diário Oficial [da] República Federativa do Brasil, Brasília, DF, 11 jul. 2001.

Lei no 12.408, de 25 de maio de 2011. Altera o art. 65 da Lei no 9.605, de 12 de fevereiro de 1998, para descriminalizar o ato de grafitar, e dispõe sobre a proibição de comercialização de tintas em embalagens do tipo aerossol a menores de 18 (dezoito) anos. Diário Oficial [da] República Federativa do Brasil, Brasília, DF, 26 maio 2011.

Lei no 2.848, de 7 de dezembro de 1940. Código Penal. Diário Oficial [da] República Federativa do Brasil, Brasília, DF, 7 dez. 1940. Disponível em: <https://goo.gl/L56zYY>. Acesso em: 23 fev. 2016.

Lei no 6.938, de 31 de agosto de 1981. Dispõe sobre a Política Nacional do Meio Ambiente, seus fins e mecanismos de formulação e aplicação, e dá outras providências. Diário Oficial [da] República Federativa do Brasil, Brasília, DF, 31 ago. 1981. Disponível em: <https://goo.gl/t4OexJ>. Acesso em: 23 fev. 2016.

Lei no 7.347, de 24 de julho de 1985. Disciplina a ação civil pública de responsabilidade por danos causados ao meio-ambiente, ao consumidor, a bens e direitos de valor artístico, estético, histórico, turístico e paisagístico (VETADO) e dá outras providências. Diário Oficial [da] República Federativa do Brasil, Brasília, DF, 7 jul. 1985. Disponível em: <https://goo.gl/uMkep5>. Acesso em: 23 fev. 2016.

Lei no 9.605, de 12 de fevereiro de 1998. Dispõe sobre as sanções penais e administrativas derivadas de condutas e atividades lesivas ao meio ambiente, e dá outras providências. Diário Oficial [da] República Federativa do Brasil, Brasília, DF, 12 fev. 1998. Disponível em: <https://goo.gl//m3VvE>. Acesso em: 23 fev. 2016.

Projeto de Lei no 985 de 2015. Brasília, DF: Câmara dos Deputados, 2015a. Disponível em: <https://goo.gl/GnTcHa>. Acesso em: 23 fev. 2016.

Redação final. Projeto de Lei no 985 de 2015. Brasília, DF: Câmara dos Deputados, 2015b. Disponível em: <https://goo.gl/6xjhYu>. Acesso em: 23 fev. 2016.

Resolução no 34, de 1 de julho de 2005. Dispõe sobre as sanções penais e administrativas derivadas de condutas e atividades lesivas ao meio ambiente, e dá outras providências. Diário Oficial [da] República Federativa do Brasil, Brasília, DF, 14 jul. 2005. Disponível em: <https://goo.gl/pByFRL>. Acesso em: 23 fev. 2016.

CARVALHO, C. de O.; RODRIGUES, R. O direito à cidade. Rio de Janeiro: Lumen Juris, 2016.

CARVALHO, Salo de. Das subculturas desviantes ao tribalismo urbano (itinerários da criminologia cultural através do movimento punk). In: LINCK, José Antônio Gerzson et al. Criminologia cultural e rock. Rio de Janeiro: Lumen Juris, 2011. p. 149-223. 
DJAN, C. A criminalização da pixação. Revista Vaidapé, São Paulo, v. 4, p. 44-49, 6 mar. 2015.

EMICIDA. A rua é nois. Intérprete: Emicida. In: Emicida. O glorioso retorno de quem nunca esteve aqui. Salvador: Laboratório Fantasma, p2013. Disponível em: <https://goo.gl/GCJSP3>. Acesso em: 23 fev. 2016.

FÓRUM SOCIAL DAS AMÉRICAS; FÓRUM MUNDIAL URBANO. Carta mundial do Direito à Cidade. 2004. Disponível em: <https://goo.gl/g6PWsA>. Acesso em: 23 fev. 2016.

GAIO, Daniel. A interpretação do direito de propriedade em face da proteção constitucional do meio ambiente urbano. Rio de Janeiro: Renovar, 2015.

GALIL, Aidê Maria Guarnieri. O Direito Urbanístico no Brasil: aspectos estratégicos para a elaboração do Plano Diretor. 2005. Disponível em: <https://goo.gl/U3iAZ7>. Acesso em: 23 fev. 2016.

IASI, Mauro. A Rebelião, a Cidade e a Consciência. In: HARVEY, D.; MARICATO, E. (Org.). Cidades rebeldes. São Paulo: Boitempo, 2013.

LARRUSCAHIM, P. G.; SCHWEIZER, P. A criminalização da pixação como cultura popular na metrópole brasileira na virada para o século XXI. R. Dir. Gar. Fund., Vitória, v. 15, n. 1, p. 13-32, jan./jun. 2014. Disponível em: <https://goo.gl/HItTGx>. Acesso em: 23 fev. 2016.

LEFEBVRE, Henri. O direito à cidade. 4. ed. São Paulo: Documentos, 2006.

LEMINSKI, Paulo. Distraídos venceremos. 2008. Disponível em: <https://goo.gl/fgXf9i>. Acesso em: 23 fev. 2016.

Toda poesia. São Paulo: Companhia das Letras, 2013.

MARICATO, Ermínia. Metrópole na Periferia do Capitalismo: ilegalidade, desigualdade e violência. São Paulo: Editora Hucitec, 1996.

PASSAPUSSO. Terapia. Intérprete: BaianaSystem. In: BaianaSystem. Terapia - Single. Salvador: BaianaSystem, p2013. 1 CD. Faixa 1. Disponível em: <https://goo.gl/DN38zg>. Acesso em: 23 fev. 2016.

REVISTA DIREITO E SENSIBILIDADE. 2011. Disponível em: <https://goo.gl/Uq22Oo>. Acesso em: 23 fev. 2016.

SILVA, J. A. Direito urbanístico brasileiro. São Paulo: ERT, 1981.

SOUSA JÚNIOR, José Geraldo de. Direito como liberdade: o Direito achado na rua (Experiências populares emancipatórias de criação do Direito). 2008. 338 f. Tese (Doutorado em Direito)Faculdade de Direito, Universidade de Brasília, Brasília, 2008.

SOUZA, P. B. Do valor de uso ao valor de troca: a transformação de espaços públicos para fins de consumo. 2014. Disponível em: <https://goo.gl/uhsPP9>. Acesso em: 23 fev. 2016. 
WAISELFISZ, J. J. Mapa da violência 2014. 2014. Disponível em: <https://goo.gl/Lvwxkg>. Acesso em: 23 fev. 2016.

WARAT, Luis Alberto. A rua grita Dionísio! Direitos Humanos da alteridade, surrealismo e cartografia. Rio de Janeiro: Lumen Juris, 2010.

Trabalho enviado em 25 de janeiro de 2017.

Aceito em 09 de maio de 2017. 